\title{
Resenha:
}

\section{DONALD WOODS: homem de convicções e coragem!}

WilsonGomes deAlmida1

É verdade que enquanto instituição formal, o regime do apartheidda África do Sul desintegrou-se, a partir das eleições multipartidárias que conduziram Nelson Mandela, histórico líder do Congresso Nacional Africano (ANC), à presidência do país, embora do ponto de vista da práxis essa não é sabidamente uma questão resolvida. Muito pelo contrário, a realidade pós-aparthèdé bem diversa, e ao mesmo tempo muito dolorosa para as maiorias desprovidas dos meios de produção. Prevalece, portanto, a certeza de que é da responsabilidade exclusiva dos cidadãos da África do Sul a hercúlea tarefa de construir em novas bases a sociedade matizada do rancor que se revela através das profundas cicatrizes e das muitas chagas abertas com os traumas e ressentimentos que periclitam entre a latência $\mathrm{e}$ a conflagração, herdada dos sombrios anos do domínio branco.

As razões profundas para esses traumas e ressentimentos que nem o tempo pode apagar, vamos encontrar nas crônicas diárias de um dos homens mais odiados pelos verdugos do regime racista sulafricano. Chama-se Donald Woods, nome inscrito no imaginário coletivo dos habitantes de paralelos e meridianos, através do filme UmGrito de Liberdade, baseado no livro de sua autoria Biko - que conta e denuncia a verdade sobre a morte do líder estudantil negro Steve Biko.

De verdade, pela sua coragem, responsabilidade sócio-político-profissional e humanismo, seu nome extrapolou todas as fronteiras do seu pás, deixando para trás as muralhas e cercas de arame farpado do apartheidpara se espraiar na consciência universal.

D onald Woods era jornalista de profissão e por anos seguidos foi editor do Daily Dispatch jomal da pequena East London, cidade da África do Sul, onde assinava regularmente uma coluna bastante concorrida e que era pelo interesse que despertava replicada em outros jornais de seu país. E, foi assim que se notabilizou internacionalmente como crítico acérrimo e inimigo confesso e irreconciliável da segregação racial.

Sua mordacidade era simplesmente demolidora. Os efeitos da sua contundente e perseverante crítica eram devastadores e incomodavam, deveræs o regime. E, como

1 Wilson Gomes de Almeida é graduado engenheiro agrônomo, mestre em Economia Agrícola e doutor em História Econômica. Pertenceu aos quadros da direção da economia na República de Moçambique durante mais de dez anos. Professor universitário e jornalista em diversos países é conhecido por seu amplo conhecimento de assuntos e temas africanos. 
incomodavam! Por isso mesmo não havia como os donos do poder racista fazerem ouvidos moucos ao seu verbo!

Dono também de uma ironia fina, mas ao mesmo tempo corrosiva e deletéria, tirava-lhes o sono, mantendo-os em estado permanente de histeria. Talvez por isso mesmo, diante de cada nova crônica publicada sentiam que precisavam ripostar, agir para pelo menos minimizar o seu elevado poder desmascarador do apartheid

Não tardou muito que o esperado aconteceu. Foi submetido à prisão domiciliar, proibido de escrever, viajar, falar em público ou ser citado pela imprensa. Restavalhe a alternativa da fuga que o levou a Londres onde residiu pelo resto de sua vida.

Por dantro do A partheid o catidiano da resistênia na África db Sul é uma compilação de uma seleta de crônicas publicadas por Donald Woods entre 1975 e 1977 no Daily Dispach Publicado no Brasil pela Editora Best Seller (São Paulo, 1988), numa tradução de Édi G . de Oliveira, contem 57 artigos, cuja leitura inquestionavelmente ajuda o leitor a penetrar nas entranhas do segregacionismo sul-africano que infelicitou a população negra e perturbou a consciência branca esclarecida por mais de meio século.

Despretensioso na sua apresentação, até por não se tratar de um volume alentado semelhante às consagradas obras do gênero, o livro de Donalds Wood carrega uma trajetória densa e profícua. Nesse sentido é praticamente impensável alguém do lado de cá do Atlântico (isso também serve para alguém do outro lado do Paćfico), que se predisponha a dissecar a essência do apartheid sem levar na devida conta o proselitismo quase doutrinário por ele realizado na incessante busca da conquista de mentes e corações na luta contra a anomia branca.

Lendo-o percebe-se o quão Donald Woods era conjoso e destemido. Não satisfeito em denunciar e desmascarar o aparthed, se sentia impelido a desafiálo, confrontando-o cotidianamente. Basta que se lhe lêem alguns dos títulos de suas crônicas, para que não restem dúvidas de que afrontar o regime permanentemente era parte essencial da sua conduta profissional enquanto jornalista comprometido com a verdade. Citemos alguns daqueles que mais enfureceram e tiraram do sério os patronos do aparthied Por trás da Máscara de Vater, Das Honens em um Banhero, Marcianos em Langklơ?; O Afrikâner Comegau na Índia; Mandda Deve Ser Libetadb, O Dia en que Joggram Fetilizante mo Ventiladar, Onde o Tempo Parar, Tarde Demis para Peguntar, Mdhror Bustos do que Bdbagens Dahau pra Crianças, Um Caso para Shedok; Sinais de Sontá, Indeisão mo Púlpita, A Mate de Um Deida, GravemBemEsteNome, Digathes para Parar, Não Temos Tempopara Tréénas; ComoFazer Biltong Carta Abeta a Varter, J'acuse; O Ministro Knuger DeeseDenitir. As parangonas falam por si 
só! Em todos eles perpassam manifestações explicitas da veia irônica, da troça penetrante e do espírito arguto do autor, mas também o clima de tensão e medo que emolduvava a ambiência onde elas foram escritas.

Como escreve Alon Paton, responsável pela seleta em apreço, J'aasse, escrita por ocasião do assassinato de Steve Biko na prisão, marcou um ponto de inflexão nas crônicas de D onald Woods, a partir da qual definitivamente "a couna mudau detomejá não havia mais brinadara". Mas foi também a partir desse momento que a intolerância do poder com 0 jomalista atingiu níveis insuportáveis.

Fica muito evidente que Comofazer Biltangaltura em que o autor pôs-se a escrever sobre a culinánia sul-africana para dar por assim dizer, um "refresco" às autoridades racistas já completamente celeradas com os seus artigos, pode ter sido um momento sintomático do que estava por vir. Para quem não conhece, o biltong amplamente consumido na África do Sul, é uma carne crua seca, de cabra, bovino ou caça, de textura consistente, salgada, apimentada e regada de um mix de temperos bem marcantes, como regra preparada artesanalmente. Mas foi com a crônica O MinistroKnuger DeeseDenitir, que a permanência de Donald Woods na África do Sul deixou de ser temerária e simplesmente arriscada e se tomou impraticável.

Nas crônicas que se sucederam à morte de Biko, Donald Woods despiu-se das quase nenhumas veleidades e pruridos que a duras penas vinha dissimulando por razões de ofício para reclamar pública e abertamente responsabilidade das autoridades, na pessoa do Ministro da Polícia, J. T. Kruger, exigindo a sua demissão sumária e uma investigação isenta sobre 0 acontecido.

E, é tão verdadeiro o fato de que a morte de Biko o marcou pofunda e indelevelmente, que não seria justo negar ao leitor essas palavras de Donald Woods ao descrever sua participação no funeral do líder estudantil covardemente assassinado (na versão oficial Biko, um obstinado pela vida, "se suicidou"), na crônica que leva por título:

\section{Uma EspóiedeMilage}

Pegueuma miltidăodevintemil negosmofuneal deumlíder queidb quemmeusdbastóda da Pdíáa de Seguranga branca; arescenteà sua raiva mis raiva pda insensibilidadedoministro da Pdíáa Knuger, ao dizer quessa mateo dixava fiio, anescettemais raiva pdo fato dea pdía impedir que autras dzenas demilhares de pessas partipassem do funeral, eacescente a raiva adiaional prowada por disarsos emeionais contra a quessão brana.

Acescente a essa agdontração denegros raivosos, aflitos, umpequem gupo debrancos misturadbs a essa enome e vdátil miltiçá Nesta tena de tensão racial, seia suficiente apenas um 
empurão, um tropegãâ, uma dostvação indlicada para provoar uma trágica explosão de realiações

Entreanto, nenhumadidete desse tipo comeu no funeral de Stere Biko eta semana. Durarte áno hras de disarsos por represetantes detocks essas arganizaçoes, supostamente antibrancas, nenhumbrano prestesetiu quenão era bemtindb au que estivessesdb amerça dirta daquda milticão enøaianadaNão que nós, os paros brancos preetes não sentíssemos medb Lange dissa. Foramas inco horas mais assustadbras deminha vida Minha esposa e eu estávamos no mio da milticão parada e sentimos mitos mometos de apreensãa pis a retóica visava a vidênia dos bramos, a cuddade dos bramos, a explaração pdos bramos, es priviéges dos brancos e a mote dos mártires negos pdos branos. A getetem mita consiênia de nosse bramara nessas œasiões..

Eram esses o tonus, a carga emocional e o realismo que emergiam sistematicamente da coluna e através da qual transbordava da redação do DailyDespachpara a África do Sul e para o Mundo as realidades da necedade racista.

Donald Woods morreu de câncer aos 67 anos de idade, em 1981, portanto, quase três décadas depois de ter escapado ileso de uma tentativa de assassinato pela polícia sulafricana - mesma ocasião em que uma camiseta envenenada foi depositada em sua casa para uso pela sua filha de 2 anos de idade.

Sobretudo para as pessoas céticas quanto à real e efetiva capacidade do indivíduo poder influenciar os destinos da história da humanidade com o seu exemplo militante, sua convicção inabalável, a determinação de predispor as demais gentes a se colocarem a mexer para mudar o status qua não importa a partir de que posição geográfica sua luta é travada (recordar que East London, de onde eram lançados os torpedos woodsianos contra Johanesburgo, Pretória, Cape Town, Durban e Port Elizabeth om estilhaços que se espalhavam pelo resto do Planeta, não passava de uma pequena cidade de menos de 200 mil habitantes), a conduta pública de Donald Woods deixa muito mais do que o exemplo de inteligência, otimismo e bravura, lega para toda a humanidade, verdadeira e inesgotável fonte de lição de vida 